\title{
Synthesis and Characterization of Acrylic Acid-g-( $\kappa$-Carrageenan) Copolymer and Study of Its Application
}

\author{
Arti Srivastava $^{1}$ and Rajesh Kumar ${ }^{2}$ \\ ${ }^{1}$ Department of Chemistry, School of Physical Sciences, Guru Ghasidas Vishwavidyalaya, Bilaspur, Chhattisgarh 495009, India \\ ${ }^{2}$ Organic Polymer Laboratory, Department of Chemistry, Centre of Advanced Studies in Chemistry, Banaras Hindu University, \\ Varanasi, Uttar Pradesh 221 005, India
}

Correspondence should be addressed to Rajesh Kumar; rkr_bhu@yahoo.com

Received 31 January 2013; Revised 16 April 2013; Accepted 16 April 2013

Academic Editor: R. J. Linhardt

Copyright (C) 2013 A. Srivastava and R. Kumar. This is an open access article distributed under the Creative Commons Attribution License, which permits unrestricted use, distribution, and reproduction in any medium, provided the original work is properly cited.

The effects of concentrations of peroxymonosulphate, mercaptosuccinic acid, hydrogen ion, acrylic acid, and carrageenan on grafting parameters were studied to find out the maximum grafting ratio. The corresponding values were found to be $14.0 \times 10^{-3}$, $32 \times 10^{-3}, 15.0 \times 10^{-3}, 18.0 \times 10^{-2} \mathrm{~mol} \mathrm{dm}^{-3}$, and $1.0 \times 10^{-2} \mathrm{~g} \mathrm{dm}^{-3}$, respectively. The optimal reaction time duration and reaction temperature were found to be $120 \mathrm{~min}$ and $40^{\circ} \mathrm{C}$, respectively. The effect of hydrogen ion variation from 5.0 up to $25.0 \times 10^{-4} \mathrm{~mol} \mathrm{dm}^{-3}$ shows prompt changes on grafting parameter. The grafted copolymer was found more thermally stable than the ungrafted substrate. Also the grafted copolymer absorbed more water, namely hazardous metal cations. $\mathrm{Hg}^{2+}, \mathrm{Pb}^{2+}, \mathrm{and}^{2+}$, showed better flocculation behavior than carrageenan.

\section{Introduction}

Currently the commercial application of natural polymers and their derivatives is most captivating and immeasurably investigated. For this purpose, biodegradable natural polymers, such as polysaccharides and protein, have been widely used $[1,2]$. Amongst the natural polysaccharides, carrageenan is widely applied due to its anionic nature. It is extracted from red seaweed and obtained from the cell wall of Rhodophyceae (red algae) belonging mainly to the genera Chondrus, Gigartina, Kappaphycus, and Eucheuma $[3,4]$. Carrageenan is a linear polymer of about 25,000 galactose derivatives with regular but imprecise structures, depending on the source and extraction conditions. Carrageenans are usually classified according to their sulphate content. From an industrial application point of view, the most important configurations are the $\kappa$ (kappa), $\iota$ (iota), and $\lambda$ (lambda) forms; their structures differ mostly in the number of sulphated groups per disaccharide: one, two, or three for $\kappa, l$, and $\lambda$, respectively. They are composed of alternation- $(1 \rightarrow 3)$ - $\beta$-D-galactopyranose- 4 -sulfate- $(1 \rightarrow 4)$ 3,6 -anhydro- $\alpha$-D-galactopyranose- $(1 \rightarrow 3$ ) (Figure 1) which are well documented [5-9]. The presence of 3,6-anhydro$\mathrm{D}$-galactose and conformation of the pyranoside ring are responsible for their interesting rheological properties. $\kappa$ carrageenan is widely used as a thickening and gelling agent in food industry [10-12]. $\kappa$-carrageenan undergoes a coil (disordered state) to helix (ordered) transition, depending on temperature and ionic environment. Gelation is achieved through junction zones formed by the helices, leading to a three-dimensional network [5].

Gelation of $l$-carrageenan is enhanced mainly by calcium, and $\kappa$-carrageenan is enhanced by potassium. It is reported [13] that cations $\mathrm{Ca}^{2+}>\mathrm{K}^{+}>\mathrm{Na}^{+}$bind to the carrageenan, blocking the sulphate groups and thereby preventing interaction with thaumatin (a basic protein). In recent years, Yuan et al. [14]. and Zhang et al. [15, 16] have demonstrated their significant role in antioxidant activities and explored them as effective excipients in controlled drug release delivery systems $[17,18]$.

Despite their numerous applications, $\kappa$-carrageenan suffers from drawbacks like easier susceptibility of microbial attack, which is destroying the gelation. Free radical initiated 


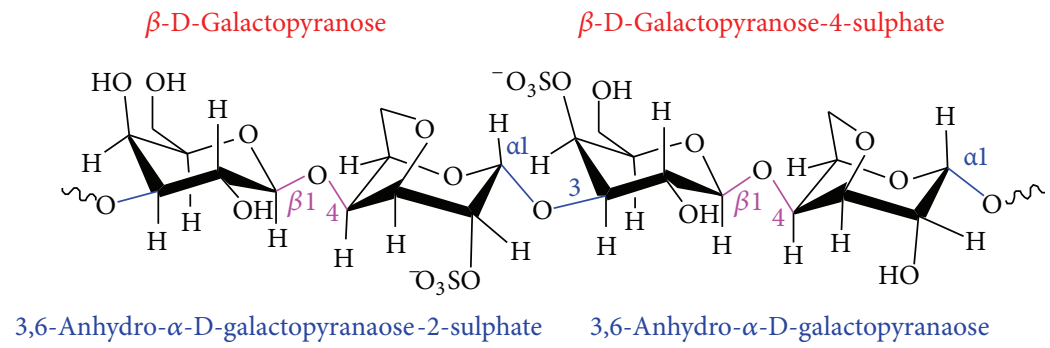

Figure 1: Structure of $\kappa$-carrageenan[-(1,3)- $\beta$-D-galactopyranose-4-sulphate-(1,4)-3,6-anhydro- $\alpha$-D-galactopyranasoe(1,3)-].

graft copolymerization provides green and efficient approach for removing the drawback of easier susceptibility of microbial attack due to use of water, which is an easily decomposable oxidant and reductant and needs fairly lower temperature than any other radical initiated polymerization process like ATRP, RAFT, NMP, and so forth, which are generally carried out in nonaqueous media. Up to date many investigations were carried out on graft copolymerization reactions in view of preparing biopolymers-based materials [19-23]. A Few recent reports highlighted the grafting of $\kappa$-carrageenan with vinyl monomers [24-30], but no report showed the effect of grafting on gelation of carrageenan. In view of gelation properties of $\kappa$-carrageenan, this work has been carried for the first time out with an aim to tailor $\kappa$-carrageenan based hybrid materials by grafting of acrylic acid using peroxymonosulphate/mercaptosuccinic acid redox pair. The optimal grafting conditions were obtained for gelation, and studies were carried out on swelling capacity, metal ion sorption, and flocculating ability.

\section{Experimental}

2.1. Materials. Acrylic acid (Sigma-Aldrich, USA) was distilled under reduced pressure in inert atmosphere at $14^{\circ} \mathrm{C}$. Peroxymonosulphate was purchased from SigmaAldrich, USA, and mercaptosuccinic acid, sulphuric acid, and methanol were purchased from Merck, India and used as received. $\kappa$-carrageenan was purchased from Sigma-Aldrich, USA.

2.2. Synthesis of Acrylic Acid-g-(א-Carrageenan) Copolymer. The grafted copolymer of carrageenan and acrylic acid was synthesized by using peroxymonosulphate/mercaptosuccinic acid redox initiator in inert atmosphere. In each case carrageenan solution was prepared by adding a precalculated amount of carrageenan to $100 \mathrm{~mL}$ triple distilled water in a three-neck reactor to achieve the desired concentration of $1.0 \mathrm{~g} \mathrm{dm}^{-3}$. To determine the optimal conditions for the grafting of acrylic acid onto carrageenan, using $\mathrm{PMS} / \mathrm{mercaptosuccinic}$ acid as redox initiator, graft copolymerization was carried out under various reaction times, temperatures, and concentrations of PMS, mercaptosuccinic acid, carrageenan, hydrogen ion, and acrylic acid. A definite concentration of sulphuric acid $\left(15.0 \times 10^{-4} \mathrm{~mol} \mathrm{dm}^{-3}\right)$ was found essential to start the reaction. A definite amount of mercaptosuccinic acid and acrylic acid solutions, that is,
$32.0 \times 10^{-4} \mathrm{~mol} \mathrm{dm}{ }^{-3}$ and $18.0 \times 10^{-2} \mathrm{~mol} \mathrm{dm}^{-3}$, respectively, was added to the reaction mixture. The stream of nitrogen gas was passed into the solution and in peroxymonosulphate solution separately. After the desired time interval (30 min), the reaction was initiated by addition of $14.0 \times 10^{-3} \mathrm{~mol} \mathrm{dm}^{-3}$ peroxymonosulphate solution. The reaction was allowed to continue for 120 minute, after which the reaction mixture was poured into water-methanol mixture $(58: 42 \mathrm{v} / \mathrm{v})$. The grafted copolymer precipitates out, whereas polyacrylic acid remained in the solution. The graft copolymer was separated by filtration and washed with water-methanol mixture (two times) so that any homopolymer stuck to the grafted copolymer sample pass into the filtrate. The grafted copolymer thus obtained was dried in vacuum oven at $40^{\circ} \mathrm{C}$ and weighed.

2.3. Separation of Homopolymer. For the separation of homopolymer from the filtrate, a pinch of hydroquinone was added to the filtrate, and the homopolymer solution was concentrated by distillation under reduced pressure at room temperature. Thereafter, polyacrylic acid was precipitated by acidifying the reduced amount as given by [31], filtered, dried, and weighed.

\subsection{Characterization}

2.4.1. Determination of Grafting Parameters. The grafting parameters were calculated according to Fanta's (1973) definition [32] in terms of grafting ratio $(\% G)$, grafting efficiency $(\% E)$, add on $(\% A)$, conversion $(\% C)$, and homopolymer $(\% H)$ :

$$
\begin{aligned}
& \% G=\frac{\text { Weight of grafted copolymer }}{\text { Weight of } \kappa \text {-carrageenan }} \times 100, \\
& \% A=\frac{\text { Weight of synthetic polymer }}{\text { Weight of grafted copolymer }} \times 100,
\end{aligned}
$$

where synthetic polymer/polymer formed is a polymer as homopolymer and incorporated into the $\kappa$-carrageenan chain:

$$
\begin{gathered}
\% C=\frac{\text { Weight of polymer formed }}{\text { Weight of monomer charged }} \times 100, \\
\% E=\frac{\text { Weight of grafted copolymer }}{\text { Weight of polymer formed }} \times 100, \\
\% H=100-\% E .
\end{gathered}
$$


TABLE 1: Grafting ratio and swelling behavior of acrylic acid-gcarrageenan as a function of the concentration of acrylic acid. $[\mathrm{PMS}]=14.0 \times 10^{-3} \mathrm{~mol} \mathrm{dm}^{-3} ;[\mathrm{MSA}]=32.0 \times 10^{-4} \mathrm{~mol} \mathrm{dm}^{-3} ;\left[\mathrm{H}^{+}\right]=$ $15.0 \times 10^{-4} \mathrm{~mol} \mathrm{dm}^{-3} ;[\mathrm{CGN}]=1.0 \mathrm{~g} \mathrm{dm}^{-3} ;$ Time $=120 \mathrm{~min}$.; Temp $=$ $40^{\circ} \mathrm{C}$.

\begin{tabular}{lcccc}
\hline Sample Code & [Acrylic acid] $\times 10^{2} \mathrm{~mol} \mathrm{dm}^{-3}$ & $\% G$ & $P_{S}$ & $S_{R}$ \\
\hline $\mathrm{C}_{\mathrm{AA} 1}$ & 8.0 & 330.0 & 310 & 3.1 \\
$\mathrm{C}_{\mathrm{AA} 2}$ & 12.0 & 336.0 & 328 & 3.3 \\
$\mathrm{C}_{\mathrm{AA} 3}$ & 16.0 & 380.0 & 342 & 3.4 \\
$\mathrm{C}_{\mathrm{AA} 4}$ & 18.0 & 510.0 & 390 & 3.9 \\
$\mathrm{C}_{\mathrm{AA} 5}$ & 20.0 & 535.0 & 396 & 4.0 \\
$\mathrm{C}_{\mathrm{AA} 6}$ & 22.0 & 494.0 & 382 & 3.8 \\
$\mathrm{C}_{\mathrm{AA} 7}$ & 24.0 & 450.0 & 360 & 3.6 \\
\hline
\end{tabular}

$[\mathrm{PMS}]=$ concentration of potassium peroxymonosulphate, $[\mathrm{MSA}]=$ concentration of mercaptosuccininc acid, [CGN] = concentration of carrageenan.

Besides the above parameters, the rate of grafting $(\mathrm{Rg})$ was calculated according to the following formula [33]:

$$
\begin{aligned}
\operatorname{Rg}= & \frac{\text { Weight of grafted polymer }(W)}{\operatorname{Vol} .(V) \times \operatorname{time}(T) \times \text { m.wt. of AA }(M)} \\
& \times 1000\left(\mathrm{~mol} \mathrm{~L}^{-1} \mathrm{~s}^{-1}\right),
\end{aligned}
$$

where $W=$ Weight of grafted gum - weight of ungrafted gum.

To determine the optimal condition for the grafting of acrylic acid onto carrageenan, using PMS/mercaptosuccinic acid as redox initiator, graft copolymerization was carried out under various reaction times, temperatures, and concentrations of PMS, mercaptosuccinic acid, carrageenan, hydrogen ion, and acrylic acid.

2.4.2. Techniques. FT-IR spectra on $\mathrm{KBr}$ disc were recorded on a Varian Excalibur 3000 (Palo Alto, CA) spectrophotometer in the region $4000-400 \mathrm{~cm}^{-1}$. The electronic absorption spectra was recorded on Perkin Elmer-Lambda 35 UV-VIS spectrometer connected with PTP-1 Peltier system at $25^{\circ} \mathrm{C}$. The optical path length of measurement cell was $10 \mathrm{~mm}$. The thermal behavior of pure carrageenan and acrylic acid-gcarrageenan was recorded on a Perkin Elmer and Diamond TG/DTA thermal analyzer within a temperature range 25$1000^{\circ} \mathrm{C}$ at a heating rate of $15^{\circ} \mathrm{C} / \mathrm{min}$ in $\mathrm{N}_{2}$.

\subsection{Studies on Properties}

2.5.1. Swelling Test. The swelling behavior of polyacrylic acid was carried out in water for one hour, and the sample was prepared by taking the different grafting ratios (Table 1) of acrylic acid. These studies were carried out by adding $0.100 \mathrm{~g}$ of poly(acrylic acid) into $20 \mathrm{~mL}$ triple distilled water and keeping undisturbed for 120 minutes at constant temperature to get the swelling equilibrium. The surface water on the swollen polyacrylic acid was removed by safely pressing between the folds of the moisten filter paper, and weights were taken. Percent swelling $\left(P_{S}\right)$ and swelling ratio $\left(S_{R}\right)$ have been calculated by using the following expressions [34]:

$$
\begin{aligned}
& P_{S}=\frac{\text { Weight of swollen polymer }- \text { Weight of the dry polymer }}{\text { Weight of the dry polymer }} \\
& \times 100, \\
& \qquad S_{R}=\frac{P_{S}}{100} .
\end{aligned}
$$

2.5.2. Viscosity Measurement. Viscosity measurements of the aqueous solutions of carrageenan and the grafted copolymers (acrylic acid-g-carrageenan) were carried out with an Ubbelohde viscometer at $30 \pm 0.1^{\circ} \mathrm{C}$.

2.5.3. Absorption of Metal Ions: Removal of Hazardous Metal Ions. The metal-ion sorption studies were carried out on the different grafted copolymers obtained by varying the concentration of acrylic acid (Table 2). For this, $0.05 \mathrm{~g}$ acrylic acid-g-carrageenan with different molecular weight were placed in a $5 \mathrm{~mL}$ solution of a metal ion with a known concentration and kept for $24 \mathrm{~h}$. After $24 \mathrm{~h}$ absorption, the concentration of the metal solution was determined by a standard method [35]. For the metal-ion sorption studies, five metal ions were selected, namely, $\mathrm{Cu}^{2+}, \mathrm{Ni}^{2+}, \mathrm{Zn}^{2+}, \mathrm{Pb}^{2+}$, and $\mathrm{Hg}^{2+}$. The sorption behavior of the polymer for those five metal ions was investigated in terms of the following parameters [36]:

Percent ion uptake $\left(P_{u}\right)$

$$
=\frac{\text { Amount of metal ion in the polymer }}{\text { Amount of metal ion in the feed }} \times 100 \text {, }
$$

Partition coefficient $\left(K_{d}\right)$

$$
\begin{aligned}
= & \frac{\text { Amount of metal ion in the polymer }}{\text { Amount of the metal ion left in the solution }} \\
& \times \frac{\text { Volume of the solution }(\mathrm{mL})}{\text { Weight of the dry polymer }(\mathrm{mg})},
\end{aligned}
$$

Retention Capacity $\left(Q_{r}\right)$

$$
=\frac{\text { Amount of metal ion in the polymer }}{\text { Weight of the dry polymer }} \text {. }
$$

2.5.4. Flocculation Test. Into a $1 \mathrm{~L}$ beaker, $200 \mathrm{~mL}$ of $1 \mathrm{wt} \%$ coal suspension was added. The beaker was placed on flocculator (Sonar Jar Set Digital Apparatus), dipping the stirrer blade in the suspension. At a $100 \mathrm{rpm}$ stirring condition, a required quantity of polymer solution was added to the beaker to make a predetermined dose with respect to suspension volume. After the addition of the polymer solution, the suspension was stirred at a constant rpm (600) for $15 \mathrm{~min}$. The flocks were allowed to settle down for one hour. Clean supernatant liquid was drawn from a depth of $1.0 \mathrm{~cm}$, and its turbidity was measured using a digital 
TABLE 2: Metal ion sorption.

\begin{tabular}{|c|c|c|c|c|c|c|c|c|c|c|c|c|c|c|c|c|}
\hline \multirow{2}{*}{ Sample Code } & \multirow{2}{*}{$\% G$} & \multicolumn{5}{|c|}{ Percent ion uptake $\left(P_{u}\right)$} & \multicolumn{5}{|c|}{ Partition coefficient $\left(K_{d}\right)$} & \multicolumn{5}{|c|}{ Retention capacity $\left(Q_{r}\right)$} \\
\hline & & $\mathrm{Cu}^{2+}$ & $\mathrm{Ni}^{2+}$ & $\mathrm{Zn}^{2+}$ & $\mathrm{Pb}^{2+}$ & $\mathrm{Hg}^{2+}$ & $\mathrm{Cu}^{2+}$ & $\mathrm{Ni}^{2+}$ & $\mathrm{Zn}^{2+}$ & $\mathrm{Pb}^{2+}$ & $\mathrm{Hg}^{2+}$ & $\mathrm{Cu}^{2+}$ & $\mathrm{Ni}^{2+}$ & $\mathrm{Zn}^{2+}$ & $\mathrm{Pb}^{2+}$ & $\mathrm{Hg}^{2+}$ \\
\hline $\mathrm{C}$ & - & 3.1 & 2.1 & 1.8 & 4.1 & 1.0 & 16.1 & 5.4 & 4.8 & 10.8 & 5.2 & 1.5 & 0.50 & 0.5 & 1.0 & 0.5 \\
\hline $\mathrm{C}_{\mathrm{AAl}}$ & 330 & 5.18 & 4.73 & 3.80 & 4.16 & 3.27 & 27.35 & 24.83 & 19.76 & 21.73 & 16.91 & 2.5 & 2.3 & 2.0 & 2.1 & 1.6 \\
\hline $\mathrm{C}_{\mathrm{AA} 2}$ & 336 & 7.88 & 6.79 & 5.32 & 6.15 & 4.49 & 42.79 & 36.42 & 28.11 & 32.76 & 23.55 & 3.8 & 3.3 & 2.8 & 3.1 & 2.2 \\
\hline $\mathrm{C}_{\mathrm{AA} 3}$ & 380 & 9.54 & 8.43 & 7.60 & 8.13 & 6.33 & 52.75 & 46.06 & 41.15 & 44.27 & 33.84 & 4.6 & 4.1 & 4.0 & 4.1 & 3.1 \\
\hline $\mathrm{C}_{\mathrm{AA} 4}$ & 510 & 8.09 & 7.40 & 5.13 & 6.94 & 4.90 & 44.01 & 40.00 & 27.05 & 37.31 & 25.80 & 3.9 & 3.6 & 2.7 & 3.5 & 2.4 \\
\hline $\mathrm{C}_{\mathrm{AA} 5}$ & 535 & 4.97 & 4.11 & 2.66 & 3.57 & 2.45 & 26.20 & 21.46 & 13.67 & 18.51 & 12.57 & 2.4 & 2.0 & 1.4 & 1.8 & 1.2 \\
\hline
\end{tabular}

Nephelometer (Eutech Instruments Digital Turbidity Meter TN-100 supplied by Merck, India). The turbidity is expressed in nephelometric unit (NTU).

\section{Results and Discussion}

3.1. FTIR Analysis. The FTIR spectrum of acrylic acidg-carrageenan showed the peaks of poly(acrylic acid) as well as carrageenan (Figure 2). The following additional peaks/bands in the spectrum of acrylic acids-g-carrageenan were observed. The broad band of the hydrogen bonding with carboxylic group - $\mathrm{OH}$ stretching disappeared from the region $3000-3500 \mathrm{~cm}^{-1}$ in graft copolymer spectrum, while the band at $2730-3050 \mathrm{~cm}^{-1}$ is attributed to stretching vibration of nonhydrogen bonded $\mathrm{OH}$ stretching. This suggests that the polymeric network is arranged in such a way that the possibility of hydrogen bonding is diminished. The peak at $1740 \mathrm{~cm}^{-1}$ is attributed to stretching vibration of carbonyl group of acrylic acid. The broad and intense bands centered at $1240 \mathrm{~cm}^{-1}$ and $1450 \mathrm{~cm}^{-1}$ are attributed to C$\mathrm{O}$ stretching and $\mathrm{C}-\mathrm{O}-\mathrm{H}$ bending vibrations. The presence of these bands/peaks confirms the grafting of poly(acrylic acid) onto carrageenan backbone. Thus, the presence of these bands and disappearance of $\mathrm{O}-\mathrm{H}$ bending vibration in the spectrum of carrageenan prove that acrylic acid was grafted onto $\mathrm{O}-\mathrm{H}$ site of the carrageenan macromolecule.

3.2. UV Analysis. Figure 3 shows UV visible spectra of acrylic acid and carrageenan-g-acrylic acid in the region 200 to $400 \mathrm{~nm}$. UV-visible spectrum of carrageenan shows the sharp peak at $223 \mathrm{~nm}$ and a broad shoulder between 300 and $340 \mathrm{~nm}$, while no absorption has been seen in the spectrum of acrylic acid. The spectrum of carrageenan-g-acrylic acid clearly indicates the incorporation of the above peak in the graft copolymer with major shift of the peak appeared at $223 \mathrm{~nm}$ to $280 \mathrm{~nm}$ and shoulder between 340 and $403 \mathrm{~nm}$. These peaks and shoulders are due to carbonyl chromophore of acrylic acid, which confirms the grafting of acrylic acid onto carrageenan.

\subsection{Studies on Properties}

3.3.1. Swelling Studies. The effect of swelling behavior on grafting ratio was studied by varying the concentration of acrylic acid from 8.0 to $24.0 \times 10^{-2} \mathrm{~mol} \mathrm{dm}^{-3}$ (Table 1). It

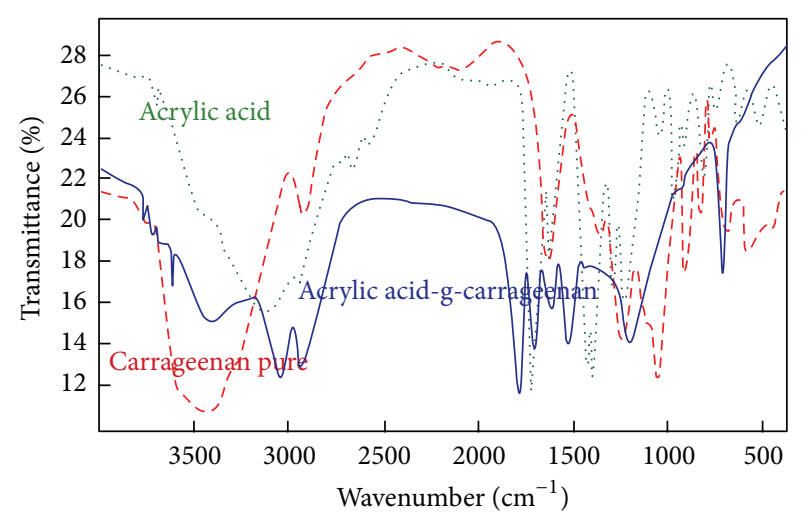

FIGURE 2: FTIR spectra of acrylic acid, carrageenan, and acrylic acid-g-carrageenan.

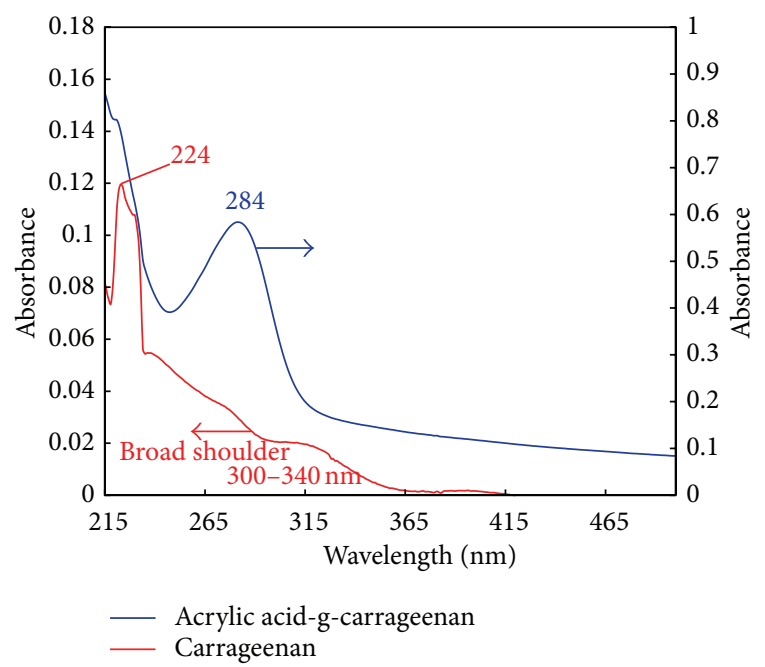

FIGURE 3: UV-visible spectra of acrylic acid-g-carrageenan and carrageenan.

was observed that percent swelling and swelling ratio of the grafted copolymer increase with increasing the grafting ratio. This is due to the hydrophilic nature of acrylic acid. The increase in percentage of poly (acrylic acid) chain on to carrageenan provides more hydrophilicity to graft copolymer thereby increases in percent swelling and swelling ratio were observed. 


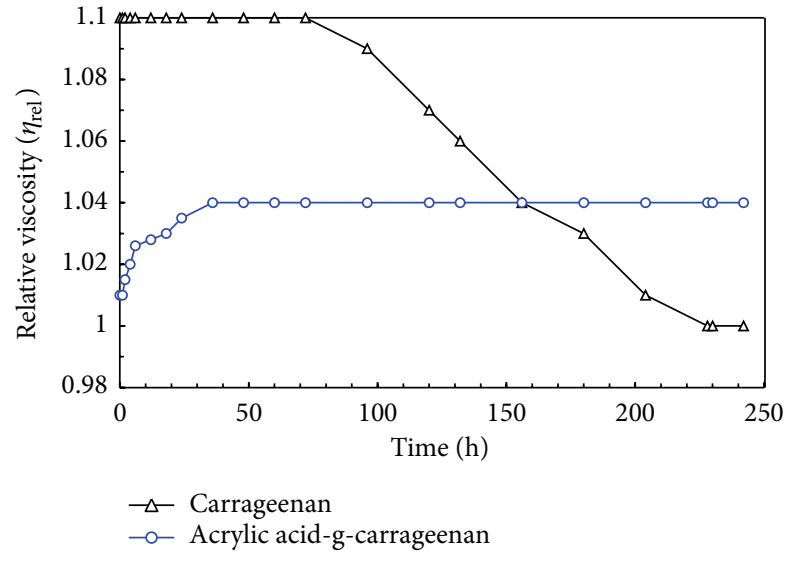

FIGURE 4: Relative viscosity of pure carrageenan and acrylic acid-gcarrageenan as a function of time.

3.3.2. Resistance to Biodegradation. If two polymers have a similar molecular weight, a branched polymer's hydrodynamic volume will be lower, and hence it will have a lower viscosity than the linear polymer. It was observed that relative viscosity of acrylic acid-g-carrageenan is lower than the carrageenan (Figure 4). This might be due to the presence of grafted chains, which make the molecule more flexible and reduce the viscosity drastically [37]. Initially up to 40 hours, viscosity of the grafted copolymer solution was increased that was due the swelling nature of polyacrylic acid chains, which absorbs water resulting in swelling in grafted copolymer. Carrageenan, like other polysaccharide solutions, is highly prone to biodegradation, and it was found that its solution after $70 \mathrm{~h}$ of preparation started to degrade, and after 10 days, the solution showed considerable loss of viscosity (Figure 4). The graft copolymer solution was subjected to the same type of study for biodegradation, and it was observed that graft copolymer solution showed no loss of viscosity up to 10 days (Figure 4). These results show that the grafted copolymer is less susceptible to biodegradation, and similar results were reported by others [37] also. This is in agreement with the fact that by incorporating relatively poly(acrylic acid) chains onto carrageenan, the carrageenan can be made less susceptible to bacterial attack [38]. Thus, it can be concluded that, by incorporation of poly(acrylic acid) onto carrageenan through graft copolymerization, the resistance to biodegradation of carrageenan can be improved.

3.3.3. Metal Ion Sorption: Removal of Hazardous Metal Ions. Hydrophilic-hydrophobic balance and nature of monomer are major factors that affect the metal ion uptake [39]. These functionalities can be tailored and incorporated by grafting to retain metal ions by polymer analogous reaction or by simple chelation absorption due to the opening of polymer matrix or pores created. Out of these possibilities, all may contribute in the metal ion sorption, although the extent of contribution of possibilities may vary [40]. However, functional group incorporated with the help of grafting by its ability to interact with metal ions may play more important

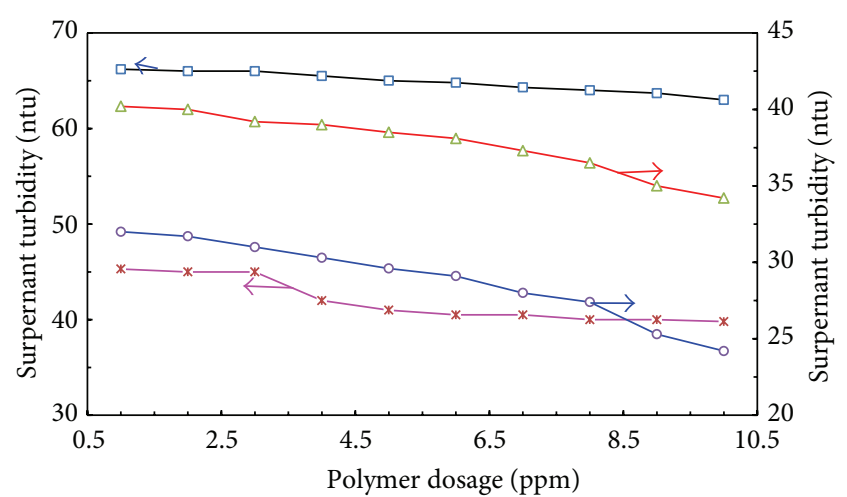

$$
\begin{array}{ll}
\rightarrow-\text { Carrageenan }^{*} & -*-\text { Carrageenan } \\
\multimap-\text { Acrylic acid-g-carrageenan }^{*} & \multimap-\text { Acrylic acid-g-carrageenan }
\end{array}
$$

FIGURE 5: Effect of polymer dosage on turbidity for coking coal and non-coking coal (shown with ${ }^{*}$ ).

role in determination of selectivity and quantum of metal ion absorption [41]. Five metal ions were chosen $\left(\mathrm{Cu}^{2+}, \mathrm{Ni}^{2+}\right.$, $\mathrm{Zn}^{2+}, \mathrm{Pb}^{2+}$, and $\mathrm{Hg}^{2+}$ ) for the study of metal ion sorption. The amount of metal ion absorption was calculated by titrating the unabsorbed metal ions. The increases in the values of $P_{u}$, $K_{d}$, and $Q_{r}$ up to $380 \% G$ (Table 2) might have been caused by the increase in poly(acrylic acid) chains, which accounts for the higher absorption of these divalent cations through a chelating reaction [42]. The highest percent ion uptake was found for Copper ions, while the lowest percent ion uptake was for mercury ions. The decreases in the values of $P_{u}, K_{d}$, and $Q_{r}$ when the grafting ratio was higher than 380 are due to the increase in viscosity of the medium.

3.3.4. Flocculation Behaviour. Flocculation efficiencies of carrageenan backbone and its poly(acrylic acid) grafted copolymer were measured by the turbidity value of the supernatant liquid. Plots of polymer dosage versus supernatant turbidity for coking and noncoking coals are presented in Figure 5. It was found that grafted copolymer showed better performance with low turbidity than the pure substrate. In the grafted copolymer, the hanging of poly(acrylic acid) chains led to better accessibility to the contaminant coal particles and hence resulted in higher flocculation potential. Here, the bridging mechanism operates which involves binding or bridging individual particles. Poly(acrylic acid) has stronger bridging mechanism than carrageenan. By forming good flocks, the flocculation potential of carrageenan was improved. By grafting of poly(acrylic acid) onto carrageenan, efficient flocculants were obtained, and they might be used for the treatment of coal waste water.

3.4. Mechanism. A mechanism has been proposed for the reaction containing carrageenan, acrylic acid, hydrogen ion, mercaptosuccinic acid, and peroxymonosulphate. It was observed that potassium peroxymonosulphate is not able to produce grafted copolymer alone. Hence, $R^{\bullet}$ free radicals are generated by the interaction of peroxymonosulphate and 


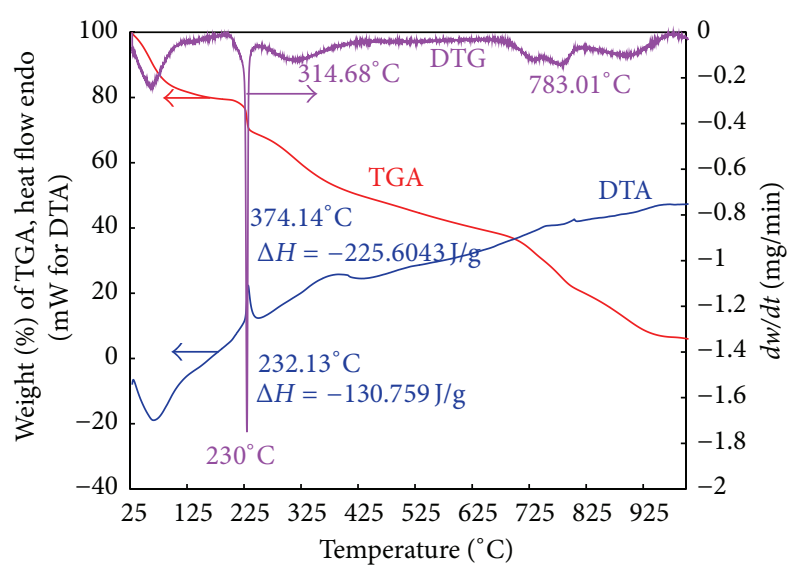

FIgURE 6: Thermal curves of TGA, DTG, and DTA of pure carrageenan.

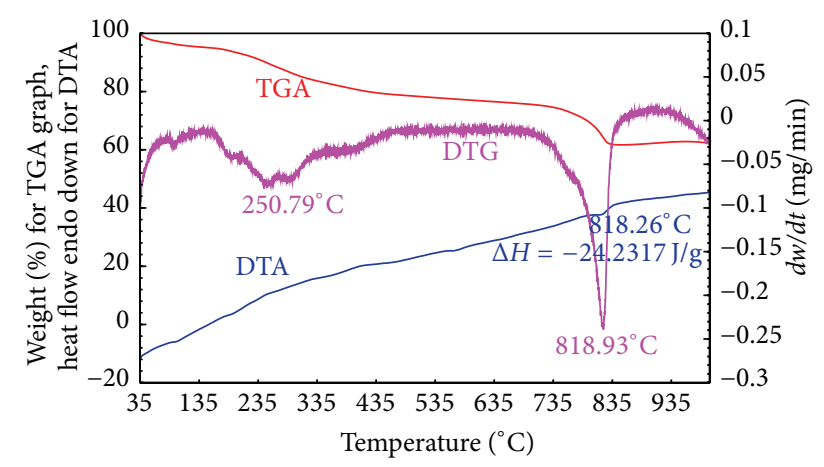

Figure 7: Thermal curves of TGA, DTG, and DTA of acrylic acidg-carrageenan.

mercaptosuccinic acid. These free radicals abstract hydrogen atoms from the carrageenan molecule producing carrageenan macroradicals. The monomer radicals which are at the close proximity of the reaction sites become acceptors of the carrageenan radicals, resulting in chain initiation, and thereafter, themselves become free radical donors to neighbouring molecules to give grafted chain. These grafted chains are terminated by coupling to give grafted copolymer.

\subsection{Thermal Analysis}

3.5.1. Carrageenan. Figure 6 presents the thermograms of carrageenan, which revealed that decomposition of carrageenan had a two-step degradation process. The $18 \%$ weight loss at $100^{\circ} \mathrm{C}$ might be due to the loss of absorbed water. It started to degrade at $200-240^{\circ} \mathrm{C}$. The polymer decomposition temperature (PDT) was found to be $125^{\circ} \mathrm{C}$. The rate of weight loss increased with the increase in temperature from $125^{\circ} \mathrm{C}$ to $240^{\circ} \mathrm{C}$ and thereafter decreased and attained a maximum value at about $230^{\circ} \mathrm{C}$. $T_{\max }$, temperature at which maximum degradation occurred, was $230^{\circ} \mathrm{C}$. The final decomposition temperature (FDT) and integral procedural decomposition temperature (IPDT) were found to be $800^{\circ} \mathrm{C}$ and $305^{\circ} \mathrm{C}$, respectively.
3.6. Acrylic Acid-g-Carrageenan. Thermogram of acrylic acid-g-carrageenan (Figure 7) showed a two-step degradation process. Acrylic acid-g-carrageenan started to degrade at about $150^{\circ} \mathrm{C}$; however, $4 \%$ weight loss was observed around $100^{\circ} \mathrm{C}$, which was due to the absorbed water. The rate of weight loss was very slow up to $730^{\circ} \mathrm{C}$. Only $25 \%$ weight loss was observed up to this temperature, while pure substrate degraded by almost $80 \%$ at $700^{\circ} \mathrm{C}$, but after $730^{\circ} \mathrm{C}$, acrylic acid-g-carrageenan degraded rapidly (Figure 7 ). The maximum weight loss $\left(T_{\max }\right)$ appeared at two temperatures, that is, $251^{\circ} \mathrm{C}$ and $819^{\circ} \mathrm{C}$. And PDT, FDT, and IPDT of acrylic acidg-carrageenan were found to be $180^{\circ} \mathrm{C}, 825^{\circ} \mathrm{C}$, and $376.93^{\circ} \mathrm{C}$, respectively. The PDT and FDT indicated that grafting of acrylic acid increased the initial decomposition temperature by $55^{\circ} \mathrm{C}$ while increasing the final decomposition temperature by $20^{\circ} \mathrm{C}$ than that of carrageenan. The higher values of FDT, IPDT, and char yield of grafted carrageenan compared to those of carrageenan indicated an overall improvement in thermal stability of the grafted copolymer.

\section{Conclusion}

The successful synthesis of high grafting ratio for the grafted copolymer was achieved. Grafted copolymer showed very good water swelling ability and resistance to biodegradation. Grafting is further supported by enhanced properties like metal ion uptake and flocculation efficiency. The thermal analysis data showed that the grafted copolymer was more thermally stable than the ungrafted polymer because of the higher final decomposition temperature and integral procedural decomposition temperature for the grafted copolymer as compared to substrate.

\section{Acknowledgments}

The authors thanks the Department of Chemistry, BHU, Varanasi (India), for providing spectral and analytical facilities and DST, New Delhi, for financial support in the form of Fast Track Project (SR/FTP/CS-107/2005).

\section{References}

[1] B. Jeong, Y. H. Bae, D. S. Lee, and S. W. Kim, "Biodegradable block copolymers as injectable drug-delivery systems," Nature, vol. 388, no. 6645, pp. 860-862, 1997.

[2] H. Younes and D. Cohn, "Morphological study of biodegradable PEO/PLA block copolymers," Journal of Biomedical Materials Research, vol. 21, no. 11, pp. 1301-1316, 1987.

[3] D. A. Rees, E. R. Morris, D. Thorn, and J. K. Madden, The Polysaccharides, vol. 1 of Edited by G. O. Aspinall, Academic Press, New York, NY, USA, 1982.

[4] O. Smidsrød and H. Grasdalen, "Some physical properties of carrageenan in solution and gel state," Carbohydrate Polymers, vol. 2, no. 4, pp. 270-272, 1982.

[5] G. A. De Ruiter and B. Rudolph, "Carrageenan biotechnology," Trends in Food Science and Technology, vol. 8, no. 12, pp. 389395, 1997.

[6] L. Hilliou, F. D. S. Larotonda, A. M. Sereno, and M. P. Gonçalves, "Thermal and viscoelastic properties of $\kappa / \iota$-hybrid carrageenan 
gels obtained from the Portuguese seaweed Mastocarpus stellatus," Journal of Agricultural and Food Chemistry, vol. 54, no. 20, pp. 7870-7878, 2006.

[7] S. E. Harding, K. Day, R. Dhami, and P. M. Lowe, "Further observations on the size, shape and hydration of kappacarrageenan in dilute solution," Carbohydrate Polymers, vol. 32, no. 2, pp. 81-87, 1997.

[8] M. Layahe, "Chemistry and physico-chemistry of phycocolloids," Chhiers de Biologie Marine, vol. 42, pp. 137-157, 2001.

[9] T. T. T. Thanh, Y. Yuguchi, M. Mimura et al., "Molecular characteristics and gelling properties of carrageenan family, preparation of novel carrageenan and their dilute solution properties," Macromolecular Chemical Physics, vol. 203, pp. 1523, 2002.

[10] A. D. Anderson, C. R. Daubert, and B. E. Farkas, "Rheological characterization of skim milk stabilized with carrageenan at high temperatures," Journal of Food Science, vol. 67, no. 2, pp. 649-652, 2002.

[11] L. González-Tomás and E. Costell, "Relation between consumers' perceptions of color and texture of dairy desserts and instrumental measurements using a generalized Procrustes analysis," Journal of Dairy Science, vol. 89, no. 12, pp. 4511-4519, 2006.

[12] S. Y. Hsu and H. Y. Chung, "Comparisons of 13 edible gumhydrate fat substitutes for low fat Kung-wan (an emulsified meatball)," Journal of Food Engineering, vol. 40, no. 4, pp. 279$285,1999$.

[13] S. Ohashi, F. Ura, T. Ochi, H. Lida, and S. Ukai, "Interaction of thaumatin with carrageenans. I. effects of $\mathrm{pH}$, temperature and competing cations," Food Hydrocolloids, vol. 4, no. 2, pp. 105-119, 1990.

[14] H. Yuan, J. Song, W. Zhang, X. Li, N. Li, and X. Gao, "Antioxidant activity and cytoprotective effect of $\kappa$-carrageenan oligosaccharides and their different derivatives," Bioorganic and Medicinal Chemistry Letters, vol. 16, no. 5, pp. 1329-1334, 2006.

[15] Q. Zhang, N. Li, X. Liu, Z. Zhao, Z. Li, and Z. Xu, “The structure of a sulfated galactan from Porphyra haitanensis and its in vivo antioxidant activity," Carbohydrate Research, vol. 339, no. 1, pp. 105-111, 2004.

[16] Q. Zhang, P. Yu, Z. Li, H. Zhang, Z. Xu, and P. Li, “Antioxidant activities of sulfated polysaccharide fractions from Porphyra haitanesis," Journal of Applied Phycology, vol. 15, no. 4, pp. 305310, 2003.

[17] C. Michona, C. Chapuisa, V. Langendorffb, P. Boulenguerb, and G. Cuveliera, "Structure evolution of carrageenan/milk gels: effect of shearing, carrageenan concentration and nu fraction on rheological behavior," Food Hydrocolloids, vol. 19, pp. 541547, 2005.

[18] R. Lazzarini, P. C. Maiorka, J. Liu, V. Papadopoulos, and J. Palermo-Neto, "Diazepam effects on carrageenan-induced inflammatory paw edema in rats: role of nitric oxide," Life Sciences, vol. 78, no. 26, pp. 3027-3034, 2006.

[19] R. Kumar, A. Srivastava, and K. Behari, "Graft copolymerization of methacrylic acid onto xanthan gum by $\mathrm{Fe}^{2+} / \mathrm{H}_{2} \mathrm{O}_{2}$ redox initiator," Journal of Applied Polymer Science, vol. 105, no. 4, pp. 1922-1929, 2007.

[20] R. Kumar, A. Srivastava, and K. Behari, "One-pot synthesis of a polysaccharide-based graft copolymer with an efficient redox pair $\left(\mathrm{Fe}^{2+} / \mathrm{BrO}_{3}{ }^{-}\right)$," Journal of Applied Polymer Science, vol. 107, no. 5, pp. 2883-2891, 2008.

[21] R. Kumar, A. Srivastava, and K. Behari, "Synthesis and characterization of polysaccharide based graft copolymer by using potassium peroxymonosulphate/ascorbic acid as an efficient redox initiator in inert atmosphere," Journal of Applied Polymer Science, vol. 112, no. 3, pp. 1407-1415, 2009.

[22] A. Srivastava, V. Mishra, S. K. Singh, and R. Kumar, "One pot synthesis and characterization of industrially important graft copolymer (GOH-g-ACM) by using peroxymonosulphate/mercaptosuccinic acid redox pair," E-Polymers, pp. 1-14, 2009.

[23] A. Srivastava, V. Mishra, S. K. Singh, and R. Kumar, "Vana$\operatorname{dium}(\mathrm{V}) /$ Mandelic acid initiated graft copolymerization of acrylamide onto Guar Gum in an aqueous medium," Journal of Applied Polymer Science, vol. 115, no. 4, pp. 2375-2385, 2010.

[24] A. Pourjavadi, A. M. Harzandi, and H. Hosseinzadeh, "Modified carrageenan 3. Synthesis of a novel polysaccharide-based superabsorbent hydrogel via graft copolymerization of acrylic acid onto kappa-carrageenan in air," European Polymer Journal, vol. 40, no. 7, pp. 1363-1370, 2004.

[25] S. Francis, M. Kumar, and L. Varshney, "Radiation synthesis of superabsorbent poly(acrylic acid)-carrageenan hydrogels," Radiation Physics and Chemistry, vol. 69, no. 6, pp. 481-486, 2004.

[26] A. Pourjavadi, H. Hosseinzadeh, and R. Mazidi, "Modified carrageenan. 4. Synthesis and swelling behavior of crosslinked KC-g-AMPS superabsorbent hydrogel with antisalt and $\mathrm{pH}$ responsiveness properties," Journal of Applied Polymer Science, vol. 98, no. 1, pp. 255-263, 2005.

[27] A. Pourjavadi, S. Barzegar, and F. Zeidabadi, "Synthesis and properties of biodegradable hydrogels of $\kappa$-carrageenan grafted acrylic acid-co-2-acrylamido-2-methylpropanesulfonic acid as candidates for drug delivery systems," Reactive and Functional Polymers, vol. 67, no. 7, pp. 644-654, 2007.

[28] D. K. Mishra, J. Tripathy, and K. Behari, "Synthesis of graft copolymer (k-carrageenan-g-N,N-dimethylacrylamide) and studies of metal ion uptake, swelling capacity and flocculation properties," Carbohydrate Polymers, vol. 71, no. 4, pp. 524-534, 2008.

[29] M. M. Mishra, A. Sand, D. K. Mishra, M. Yadav, and K. Behari, "Free radical graft copolymerization of $\mathrm{N}$-vinyl-2-pyrrolidone onto k-carrageenan in aqueous media and applications," Carbohydrate Polymers, vol. 82, no. 2, pp. 424-431, 2010.

[30] H. L. A. El-Mohdy and H. A. A. El-Rehim, "Radiation-induced kappa carrageenan/acrylic acid graft-copolymers and their application as catalytic reagent for sucrose hydrolysis," Chemical Engineering Journal, vol. 145, no. 1, pp. 154-159, 2008.

[31] P. Elayaperumal, T. Balakrishnan, M. Santappa, and R. W. Lenz, "A comparison of the absolute reactivity of vinyl monomers. I. Kinetic studies on radical polymerization of vinyl monomers initiated by a $\mathrm{Mn}^{3+}$-diglycolic acid redox system," Journal of Polymer Science A, vol. 20, no. 12, pp. 3325-3336, 1982.

[32] G. F. Fanta, "Block and graft copolymerization," in Synthesis of Graft and Block Copolymers of Starch, R. J. Ceresa, Ed., pp. 1-27, Wiley-Interscience, New York, NY, USA, 1973.

[33] A. Srivastava and K. Behari, "Synthesis and characterization of graft copolymer (guar gum-g-N-vinyl-2-pyrrolidone) and investigation of metal ion sorption and swelling behavior," Journal of Applied Polymer Science, vol. 100, no. 3, pp. 24802489, 2006.

[34] H. A. Abd EL-Rehim, A. Hegazy EL-Sayed, and A. M. Ali, "Selective separation of some heavy metals by poly(vinylalcohol)-grafted membranes," in Journal of Applied Polymer Science, vol. 76, pp. 125-132, 2000. 
[35] J. Basset, R. C. Denny, G. H. Jeffery, and J. Mendham, Vogel's Text Book of Quantitative Analysis, William Clowes and Sons, London, UK, 4th edition, 1978.

[36] B. L. Rivas, H. A. Maturana, M. Jesús Molina, M. R. GómezAntón, and I. F. Piérola, "Metal ion binding properties of poly(N-vinylimidazole) hydrogels," Journal of Applied Polymer Science, vol. 67, no. 6, pp. 1109-1118, 1998.

[37] S. Ungeheuer, H. W. Bewersdorff, and R. P. Singh, "Turbulent drag effectiveness and shear stability of xanthan-gum-based graft copolymers," Journal of Applied Polymer Science, vol. 37, no. 10, pp. 2933-2948, 1989.

[38] J. K. Seaman, "Locust bean gum," in Handbook of Water Soluble Gums and Resins, R. L. Davidson, Ed., pp. 6-9, McGraw-Hill, New York, NY, USA, 1980.

[39] J. Lehto, K. Vaaramaa, E. Vesterinen, and H. Tenhu, "Uptake of zinc, nickel, and chromium by $\mathrm{N}$-isopropyl acrylamide polymer gels," Journal of Applied Polymer Science, vol. 68, no. 3, pp. 355362, 1998.

[40] K. Inou, Y. Baba, and K. Yoshizuka, "Adsorption of metal ions on chitosan and crosslinked copper(II)-complex chitosan," Bulletin of the Chemical Society of Japan, vol. 66, pp. 2915-2921, 1993.

[41] P. X. Sheng, Y. P. Ting, J. P. Chen, and L. Hong, "Sorption of lead, copper, cadmium, zinc, and nickel by marine algal biomass: characterization of biosorptive capacity and investigation of mechanisms," Journal of Colloid and Interface Science, vol. 275, no. 1, pp. 131-141, 2004.

[42] E. Onsoyen and O. Skaugrud, "Metal recovery using chitosan," Journal of Chemical Technology and Biotechnology, vol. 49, no. 4, pp. 395-404, 1990. 

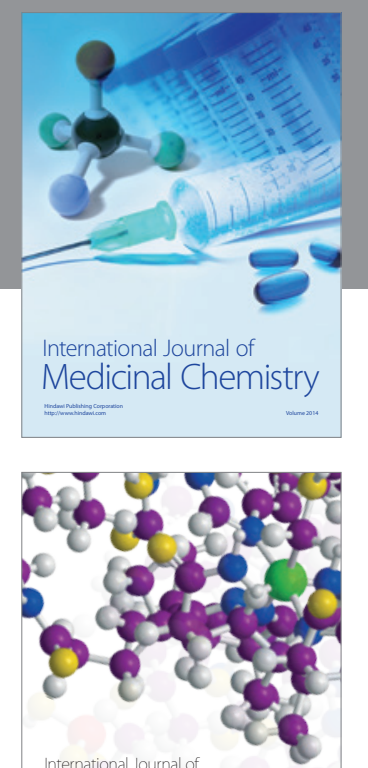

\section{Carbohydrate} Chemistry

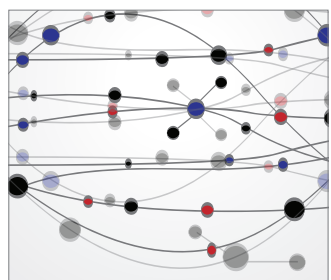

The Scientific World Journal
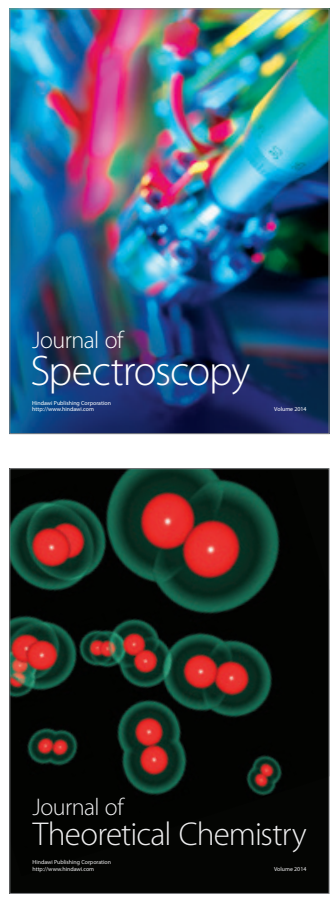
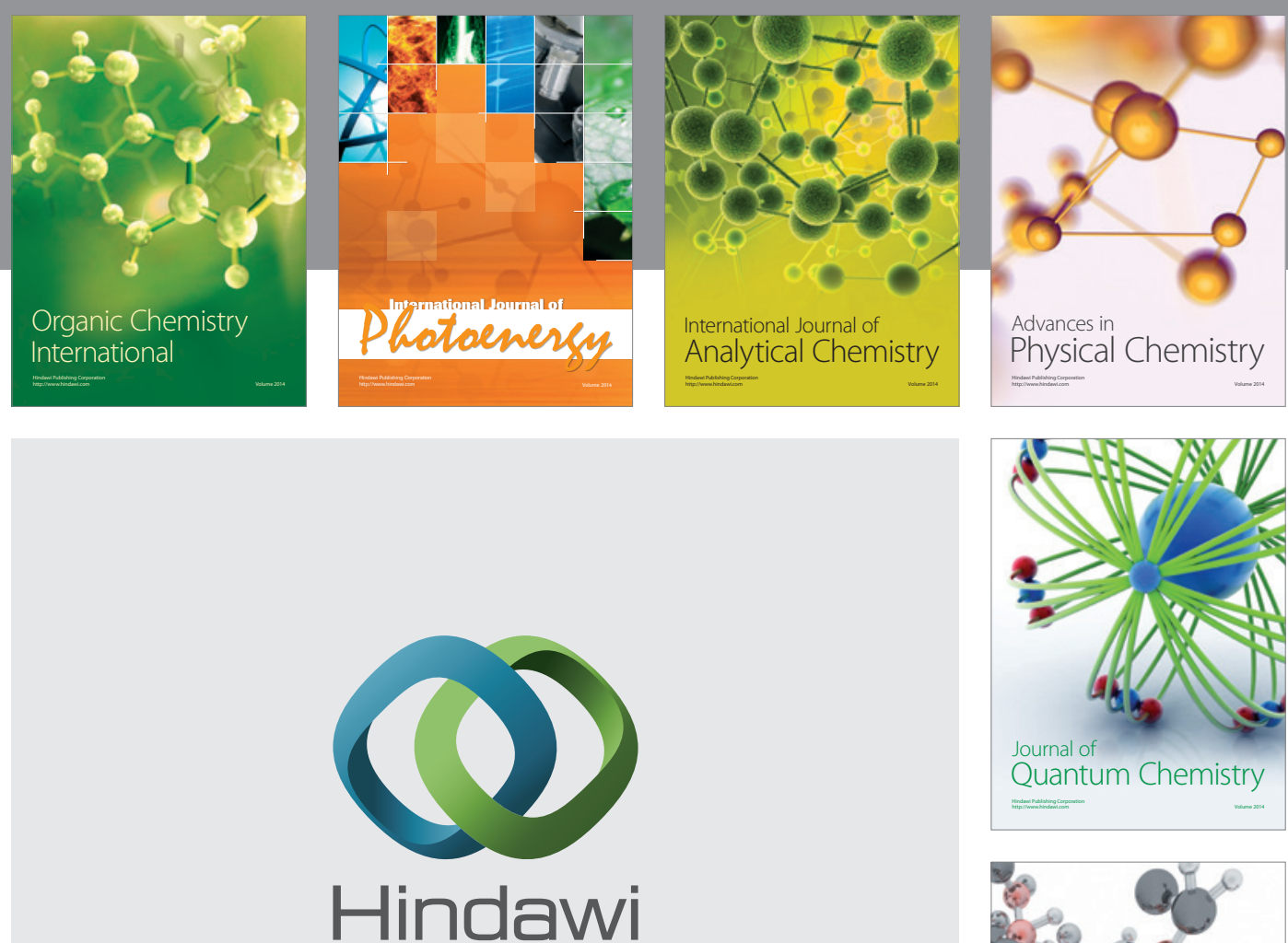

Submit your manuscripts at

http://www.hindawi.com

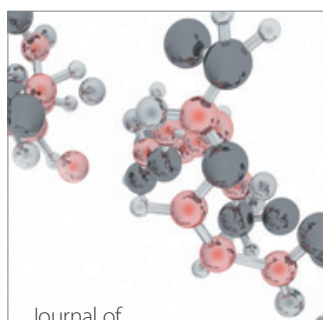

Analytical Methods

in Chemistry

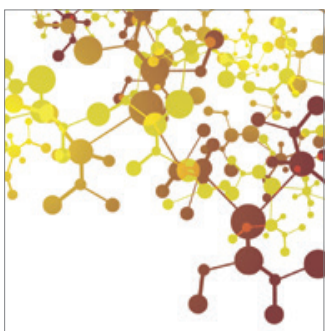

Journal of

Applied Chemistry

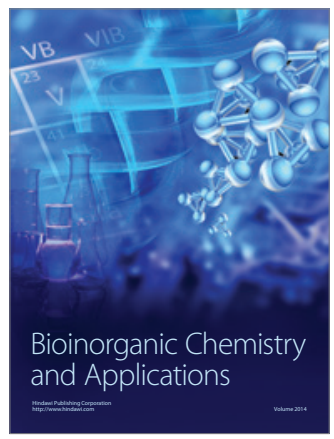

Inorganic Chemistry
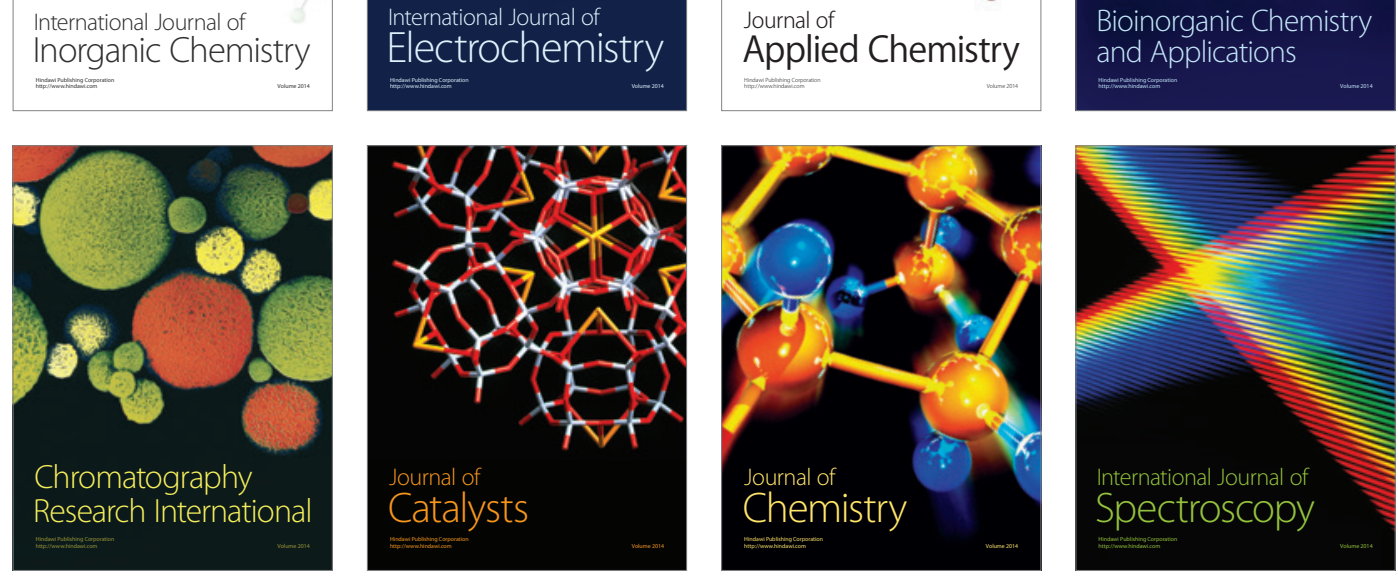